\title{
Insights into the putative role of leptin in various traversing stages of women: A narrative review
}

\author{
G. M. Saranya*, M. Ramesh Pathy \\ School of Bio Sciences and Technology, Vellore Institute of Technology (VIT) Vellore, Tamil Nadu, India.
}

\begin{tabular}{l}
\hline ARTICLE INFO \\
\hline Article history: \\
Received on: $13 / 04 / 2018$ \\
Accepted on: 25/06/2018 \\
Available online: $30 / 07 / 2018$ \\
\\
\hline Key words: \\
Leptin, puberty, fertility, \\
energy homeostasis, obesity, \\
pregnancy, menopause.
\end{tabular}

\begin{tabular}{l}
\hline ABSTRACT \\
From adolescence to adulthood, a woman goes through distinct phases in her life. The role of leptin in this journey is \\
very crucial, as it supports her to cross different milestones in time. Leptin is an indispensable factor in the metabolic \\
control of puberty, fertility, and pregnancy. Puberty is a chronic biological process that helps transform a child into \\
an adult. In this process, sufficient amount of leptin is necessary for the initiation of puberty in girls. Apart from \\
maintaining the energy homeostasis by regulating the food intake and energy expenditure, it also regulates various \\
other hormones required for reproduction and regulation of the endocrine system. Malfunction of leptin alters the \\
neuroendocrine pathways and causes a detrimental effect on reproductive disorders, such as PCOS, obesity, diabetes, \\
anorexia, and infertility which are the most important intimation for female reproductive health worldwide. In this \\
article, we aim to provide a synoptic view on the roles of leptin in the metabolic regulation of the reproductive axis, \\
its hormonal regulations, permissive role for the onset of puberty, continuity of menstrual cycle and the putative roles \\
of leptin during gestation, including its potential function as placental hormone in a female.
\end{tabular}

\section{INTRODUCTION}

Leptin is an adipocyte hormone and is also called as the master hormone of the body which is produced mostly by adipocytes and by granulosa, theca cells and cumulus cells of ovarian follicles (Kamyabi and Gholamalizade, 2015; Catteau et $a l ., 2016)$. It is a $16-k D a$ protein of 167 amino acids plays a crucial role in the regulation of energy balance and body weight control (Farhood et al., 2016). Circulating leptin binds to leptin receptor and functions as part of a signalling pathway, including Janus kinase 2 (JAK2)-signal transducer and activator of transcription 3 (STAT3), insulin receptor substrate (IRS)-phosphatidylinositol 3-kinase (PI3K), mitogen-activated protein kinase (MAPK), and 5 ' adenosine monophosphate-activated protein kinase (AMPK)/ acetyl-CoA carboxylase (ACC). Among these, the JAS/STAT3 plays an important role in the regulation of energy homeostasis (Catteau et al., 2016). In human beings, leptin and leptin receptor genes are present at chromosomal locations $7 \mathrm{q} 32.1$ and $1 \mathrm{p} 31.3$

\footnotetext{
${ }^{*}$ Corresponding Author

G. M. Saranya, Associate Professor, School of Bio Sciences and Technology, VIT Vellore, 632014.

E-mail:mrameshpathy@vit.ac.in
}

respectively. Mutation in the leptin and in its regulatory regions has been linked to type 2 diabetes mellitus development, metabolic disorders, hormonal imbalance and causes severe obesity that leads to infertility (Sanchez and Tena, 2013). It also regulates several endocrine functions and is involved in the regulation of immune and inflammatory responses, hematopoiesis, angiogenesis, reproduction, bone formation and wound healing (Nunziata et al., 2017).

Due to the influence of sex hormones and larger subcutaneous fat, women likely to have higher leptin levels than men. Low level of leptin in women will affect puberty and reproduction when leptin concentrations are adequate, the body may reduce energy stores for the sake of reproduction. During low leptin concentration that energy stores are low so it gives a signal that the body should need food for energy balance and reproduction (Naylor and Petri, 2016). Leptin has a significant position in the global obesity, increasing obesity is positively correlated to a number of anovulatory cycles and it directly inhibits ovarian steroidogenesis, leading to inoperative follicular maturation (Sroga et al., 2016). The risk of subfecundity and infertility, conception rates, miscarriage rates and pregnancy complications are increased in these women. They have poor 
reproductive outcomes in natural as well as assisted conception (David et al., 2014). In this review, we will focus on the pivotal role and association of leptin in a female during her various stages of life.

\section{METHODOLOGY}

The review was gleaned following a thorough survey of reliable and legitimate publications like Science Direct, PubMed, PubMed Central, Google Scholar, Scopus and other scientific databases without any study design restriction. The inquiry was built by using the keywords since the investigation of the role of leptin in women is less and only a few relevant reports are cited. Surplus literature was analyzed from reference lists in the subsequent journals and review articles of interest. The significant facts were compiled, analyzed as per the essence of the study and original flow diagrams were made for better understanding. Further in this review, the confines in the existing literature on relations between leptin and its pivotal role in women health was utilized.

\section{LEPTIN AS HORMONE REGULATOR}

Leptin acts as a satiety hormone as well as cell signaling hormone which is involved in regulation of body weight control through obstruction of food intake and amplification of energy expenditure (Blüher et al., 2007; Lecke et al., 2011). Two nucleus in the hypothalamus PVN (paraventricular nucleus) and ARC (arcuate nucleus) are responsible for maintaining homeostasis in our body (Gautron and Elmquist, 2011; Park and Ahima, 2015; Stieg et al., 2015). Leptin enters the bloodstream via circulatory system and binds to receptors on the ARC nucleus and stimulate the POMC (proopiomelanocortin) neuron to produce $\alpha-\mathrm{MSH}$ (Alpha-melanocyte stimulating hormone), which in turn binds to the MS4R receptor of the PVN neuron to suppress the appetite (anorexigenic effect) and to increases the metabolic rate in order to achieve homeostasis. Also, leptin inhibits the release of appetitestimulating factors by inhibiting the AgRp/NPY neuron which is responsible for the secretion of AgRP (Agouti-Related Protein) and NPY (neuropeptide Y) (Kelesidis et al., 2010). NPY binds to the NPY receptor of PVN neuron and increase the appetite (orexigenic effect) and AgRP binds to the MS4R receptor and act as an antagonist to $\alpha-\mathrm{MSH}$ and thereby increase the appetite as shown in figure 1. So a deficiency of leptin leads to frequent hunger and in turn increases the risk of developing obesity (Vehapoğlu et al., 2016; Kumari et al., 2017).

Ghrelinergic cells in the gastrointestinal tract produce ghrelin, a hormone responsible for hunger in our body. It functions as an adiposity signal as well as a neuropeptide in the central nervous system, to stimulate hunger. Ghrelin increases the orexigenic effect by stimulating the AgRp/NPY neuron present in ARC nucleus. There is a relationship between the hormones ghrelin and leptin in the regulation of hunger in the human body (Cowley et al., 2001; Budak et al., 2006; Klok et al., 2007). An increase in ghrelin will lead to hunger stimulation, while the increase in leptin will lead to its suppression. In normal condition ghrelin level is high before a meal and low after meals. In abnormal conditions, an elevated level of leptin concentration may cause leptin resistance which fools the brain to keep the ghrelin signal continuously stimulated. Administration of ghrelin in female rats produces hyperphagia by suppressing the effect of leptin and increasing arcuate nucleus production of NPY and AgRP, leading to weight gain in the tested model (Nogueiras et al., 2008; Perry et al., 2012; Abizaid and Horvath, 2012).

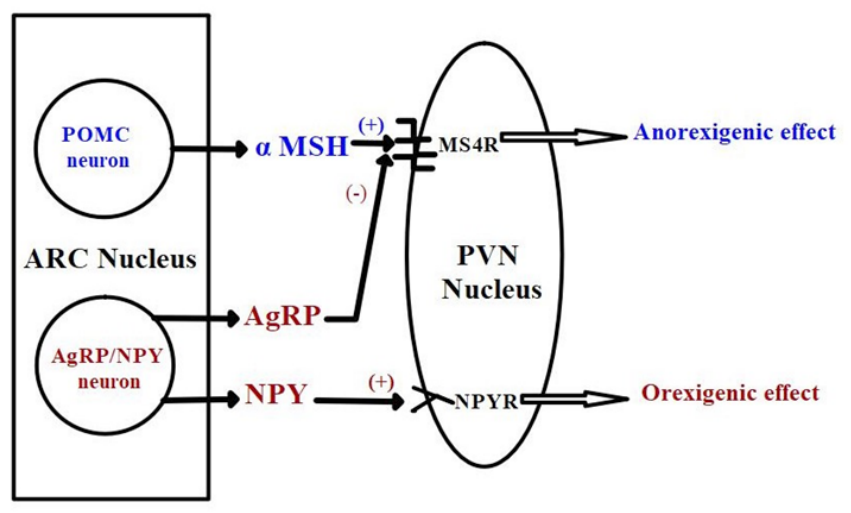

Fig. 1: Anorexigenic and orexigenic effect induced by PVN nucleus in response to the ARC nucleus. Activation of the MS4R receptor by $\alpha \mathrm{MSH}$ induces anorexigenic effect (suppress appetite), and activation of NPY receptor by NPY induces orexigenic effect (induce appetite).

Leptin acts as an energy indicator which is required for normal hypothalamic control of reproduction. The increase of leptin concentration is one of the crucial factors for hormone secretion (Louis et al., 2011; Paris et al., 2017). For instance, increased leptin level is responsible for the gonadotrophinreleasing hormone $(\mathrm{GnRH})$ secretion from hypothalamus which in turn stimulates pituitary gland leading to secretion of both follicle stimulating hormone (FSH) and luteinizing hormone in normal condition. Further these results in production and secretion of estrogen and progesterone in the ovary. Apart from causing obesity leptin deficiency and/or leptin resistance will also inhibit gonadotropin-releasing hormone $(\mathrm{GnRH})$ secretion further absence of GnRH inhibits the secretion of FSH (Follicle stimulating hormone) and LH from pituitary which may in turn cause infertility as shown in figure 2. In female mice inactivation of the POMC gene or MC3R and MC4R receptors which lead subfertility at adult age (Roseweir et al., 2008). The absence of leptin and insulin receptors from these cells causes irregularities of the estrous cycle, follicular abnormalities in the ovary and impairment of fertility (Blüher and Mantzoros, 2009; Ratra and Elias, 2014).

Yet another hormone which influences hunger, obesity, and fertility is cortisol. This neuroendocrine hormone is secreted by adrenal gland due to the abnormal factor-stress. In response to stress, the hypothalamus secretes corticotropin-releasing hormone (CRH) and NPY. A higher level of CRH will stimulate the pituitary gland to secrete ACTH which in turn will stimulate the adrenal gland to secrete cortisol. Both cortisol and NPY are responsible for orexigenic effect and hence stimulate appetite (Chou and Mantzoros, 2014). This increases the food intake and favors adipocytes to grow into mature fat cells and gets deposited deeply in the abdomen to form fat pads. It leads to intervention in the leptin - ghrelin signaling pathway by inducing leptin resistance (Leshan and Pfaff, 2014; Crujeiras et al., 2015). This mechanism indirectly results in obesity and infertility as shown in figure 2. 


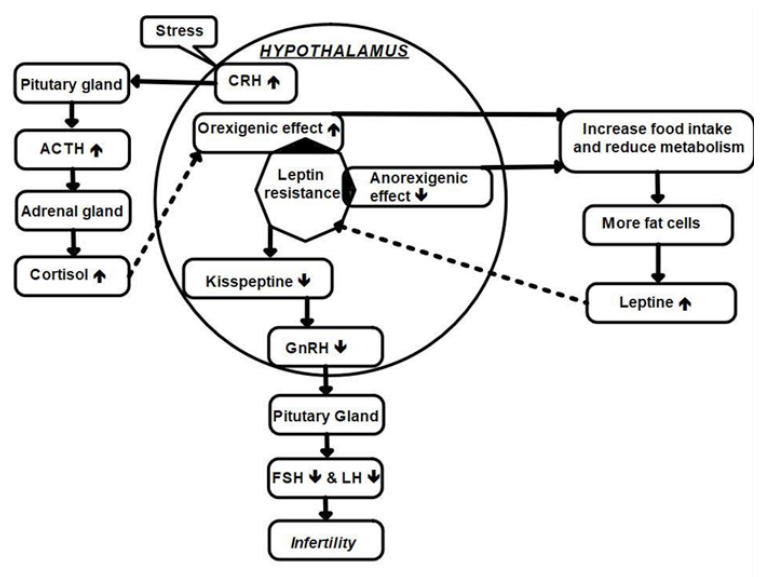

Fig. 2: Increase in orexigenic effect and decrease in anorexigenic effect due to leptin resistance and stress will lead to decrease in GnRH secretion and infertility.

\section{LEPTIN AND ITS ROLE IN PUBERTY}

The link between fat stores, puberty onset, and fertility, which was proposed by the Frisch hypothesis, was proved after the identification of leptin. Leptin is an undisputed factor in the metabolic control of puberty and fertility (Sanchez-Garrido and Tena-Sempere, 2013; Könner and Brüning, 2012; Castellano et al., 2016). Leptin plays a dynamic role in the process of puberty; it initiates the biological process required for the development of adulthood. However, the normal puberty onset plays an important role here in promoting the reproductive system development and maintaining the reproductive capacity (Elias, 2012; Hausman et al., 2012; Manfredi et al., 2016).

Puberty is regulated by interactions between kisspeptins and leptin and also the maturation of kisspeptin neurons Suprachiasmatic nucleus (SCN) is a part of the hypothalamus which is called master clock of the body to regulate puberty (Beymer et al., 2016). Kisspeptins are essential gatekeepers of mammalian puberty, and the relevance of energy homeostasis for the pubertal regulation, especially in females. Kisspeptin is found to be an intermediary between leptin signaling and $\mathrm{GnRH}$ function. Studies suggest that leptin/leptin receptor and kisspeptin/ kiss 1 receptor system plays an important role in regulating the puberty onset and the function of reproduction. Injecting leptin in prepubertal female mice hypothalamus stimulates $\mathrm{GnRH}$ secretion and subsequently, LH secretion resulting in an earlier onset of reproductive function and earlier maturation in the reproductive tract than that of controls (Luo et al., 2016). By inducing fasting or food restriction in female rat it affects the signaling pathway of the leptin/leptinR/kisspeptin/kiss1r and it decreases the GnRH neuroendocrine activity it leads delay the puberty onset it suggests leptin important for initiation of kisspeptin pathways, puberty and fertility (Clarke et al., 2015). Administration of leptin will increase the kisspeptin expression and stimulate the puberty in the female rat. These animal studies suggest that kisspeptin may stimulate GH from anterior pituitary (Semaan et al., 2013; Tng, 2015).

Kisspeptins (Kp), encoded by Kiss1 gene with the ability to activate the $G$ protein-coupled receptor, Gpr54. Inactivation of Gpr54 or Kiss1 perturbs puberty and which leads absence of puberty. Kisspeptin is an important key regulator for the mammalian reproduction, kisspeptin, acting centrally via the kisspeptin receptor, stimulates the secretion of gonadotrophin releasing hormone (GnRH) (Gueorguiev et al., 2001; Olaniyan et $a l ., 2013)$. Kisspeptin receptor gene expression has been present in both the ARC (arcuate nucleus) and AVPV (anteroventral periventricular nucleus) of the hypothalamus. Kisspeptin secreted from hypothalamus causes a chain reaction which leads to the release of neurotransmitters from the pituitary gland (Terasawa et al., 2013). These neurotransmitter signals lead to the release of other hormones such as luteinizing hormone and follicle stimulating hormone. Neurokinin B [NKB] and dynorphin [DYN] are two other neuropeptides which act as key hypothalamic regulators in reproductive function. They are used for the GnRH secretion pathways as a self-switch on and self-switch off process. DYN inhibits kisspeptin release and NKB simulates kisspeptin release (Rhie et al., 2014; Skorupskaite et al., 2014). Kisspeptin stimulates GnRH neurons to release GnRH from the hypothalamus into the hypothalamic-pituitary portal circulation which causes the release of gonadotrophs from the anterior pituitary.

The expression of kisspeptin, kiss 1r, GnRH, and leptinR were detected in the hypothalamic arcuate nucleus, surrounding the ventral surface of the third ventricle $(3 \mathrm{v})$ in the brain. The decrease of GnRH and GnRH mRNA levels subsequently caused the alteration of FSH and LH. Therefore, the changes in LH and FSH concentrations can cause abnormal development of follicle, ovulation, and luteinization. HPG axis was reactive during puberty onset and there was an increase in the expression level of GnRH and gonadal steroid hormone levels (Pan et al., 2016). Kisspeptin signaling in the hypothalamus has been important for the regulation of the GnRH pulse generator. Kisspeptin does not affect feeding but has emerged as one of the major canals to relaying body metabolic status information to GnRH neurons (De Bond and Smith, 2014).

Estrogen exerts both positive and negative feedback mechanism on kisspeptin neuron as shown in figure 3 . In positive feedback, estrogen exerts on kisspeptin neuron in AVPV, which is mediated through estrogen receptor and may account for the LH surge in the menstrual cycle. Normally estrogen allows the gonads to communicate with hypothalamus to regulate $\mathrm{GnRH}$ release, once activated HPG axis continuously work but it becomes deregulated by the lack of oocytes during menopause. This feedback effect of the estrogen regulates the expression was related with kisspeptin and kisspeptin encoding genes to mediate positive feedback effect of kisspeptin on GnRH release (Sheffer et al., 2013; Javed et al., 2015). In ARC, estrogen binds to estrogen receptor on kisspeptin neurons will inhibit kisspeptin and subsequently GnRH release (Roa et al., 2008). Estrogen exerts negative feedback on $\mathrm{GnRH}$ release which is mediated via estrogen receptor. Estrogen receptor is not expressed in GnRH neurons while it is expressed in kisspeptin neurons. In the pubertal mice high amount of leptin on the GnRH, it will block the kisspeptin pathway, these observations illustrate the negative effect of obesity-induced female infertility (Han et al., 2005; Luo et al., 2016).

\section{EFFECT OF LEPTIN IN FEMALE REPRODUCTIVE HEALTH}

Women reproductive health refers to the health of women during their reproductive years, which are the years they 
can have a child. Disorders of reproduction include low birth weight, birth defects, preterm birth, developmental disorders, menstrual disorders, reduced fertility and impotence (Crain et $a l ., 2008)$. Leptin plays a significant role in the maintenance of female reproductive health. Leptin and leptin receptors $(\mathrm{Ob}-\mathrm{Rb})$ have been identified in the hypothalamus, gonadotrope cells in the anterior pituitary, granulosa, theca, and interstitial cells of the ovary and endometrium respectively. This multifocal expression of leptin and the dense presence of leptin receptors at all levels of the hypothalamus-pituitary-gonadal (HPG) axis indicates the role of leptin in nutritional regulation and infertility (Vázquez et al., 2015; Pankov, 2015). Leptin regulation of reproduction involves a complex network of interactions at many levels to regulate the HPG axis (Goumenou et al., 2003).

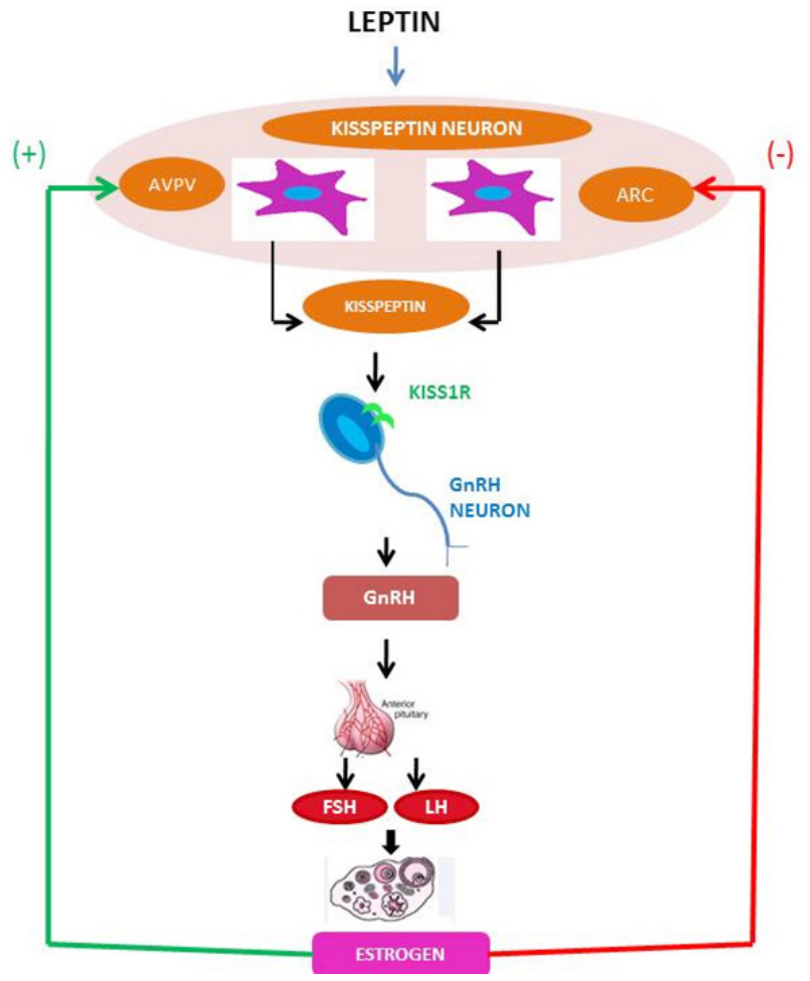

Fig. 3: Figure represents the role of kisspeptin and leptin in estrogen production from the ovary. Estrogen has a positive effect on AVPV neuron and negative effect in ARC neuron.

Leptin is performing a main role in reproductive and regulation of endocrine gland (Dardeno et al., 2010). It acts as an important signal that depends on the adequacy of nutritional status in reproductive function because insufficiency of nutrition during adulthood can lead to a reduction of GnRH and causes infertility (Zhou and Rui, 2013; Naylor and Petri, 2016). Leptin acts as an facilitator of GnRH expression, elevated level of leptin concentration, not only stimulate release of $\mathrm{GnRH}$ from hypothalamus but also stimulates LH and FSH, which are responsible for synthesizing follicular development and ovulation, the high or low amount of ovarian steroidogenesis (17-beta-estradiol (E2) and progesterone (P4)) depending on leptin concentration (Dubern and Clement, 2012). Leptin function in the ovary, there is a potential consequence in the regulation of folliculogenesis and ovulation.
The intervention of leptin signaling may lead to a pathophysiological role in reproductive disorders and metabolic alterations (Jalilian et al., 2016). Malfunction of leptin will alter the neuroendocrine pathways and causes a detrimental effect in reproductive disorders, such as PCOS, obesity, diabetes, and anorexia these are the most important intimation for female reproductive health worldwide (González et al., 2000; Gao and Horvath, 2008; Brown and Clegg, 2013). Leptin secreted from adipose reservoir affects fertility, a higher concentration of leptin provides an impact on oocyte and embryo quality leading to the destruction of endometrial bed preparation that may be involved in pregnancy failure (Unuane et al., 2011; Pérez et al., 2015). Increases in follicular fluid leptin may negatively affect the embryo development, quality, implantation and pregnancy rates (Sam and Dhillo, 2010; Karoutsos et al., 2017). Leptin might play a double-edged sword in reproduction both when leptin level is lower and higher than normal. It can exert a negative effect on reproduction, so it affects the normal functioning of ovary and development of the fetus (Patterson et al., 2012; Tsouma et al., 2014; Mutaz, 2015).

The change in concentration of different hormones related to metabolism and energy homeostasis during pregnancy have been studied (Briffa et al., 2014; Farhood et al., 2016). It is a condition where the normal functioning of the HPG axis is suppressed and in order to cope with the growing fetus's energetic demands, metabolic adaptations occur in mother. During gestation in humans, the increase in leptin level is attributed by both maternal adipose tissue and placenta (Henson and Castracane, 2000). In which, the placental leptin level is the key source of circulating leptin that leads to an increase in BMI comparatively (Salem et al., 2016; Nishimura et al., 2017). The pattern of circulating leptin concentration various during pregnancy, high level of leptin was observed in mid-gestation and it decreases subsequently in postpartum as shown in figure 4 .

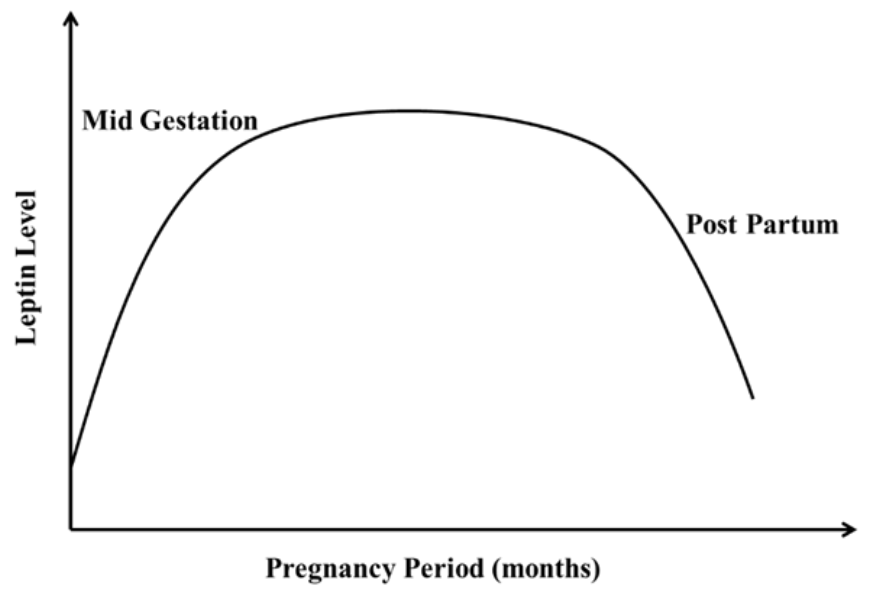

Fig. 4: Graphical representation of serum leptin level during pregnancy. Maternal leptin concentration significantly peaks at mid-gestation and gradually decreases during the postpartum period.

In humans, the maternal circulation facing syncytiotrophoblast and fetal circulation facing villous vascular endothelial cells were detected with placental leptin mRNA and a protein indicating the role of the placenta in the hyperleptinemia (Tafvizi and Masomi, 2016). The soluble isoform of leptin receptor 
(Ob-Re) expressed by human placenta reaches circulation by various ways and binds to the free leptin and thereby maintains high leptin levels in the plasma also this prevents the binding of free leptin to the other isomer of leptin receptor Ob-Rb (Anum et al., 2015). By maintaining the placental growth, fetal energy demands and a state of positive energy balance in mother, the energy accumulation during gestation is favored by an elevated level of maternal leptin which is linked to a state of central leptin resistance that works as a compensatory mechanism to store the energy resources in preparation to the metabolic demands of lactation (Herrid et al., 2014). Human Chorionic Gonadotropin (hCG) is the placental hormone that increases placental leptin synthesis and secretion in early pregnancy (Joo et al., 2010). The hCG levels increase rapidly during early pregnancy and decrease during the latter part of the first trimester and are maintained at low concentrations throughout gestation which is presented in figure 5 .

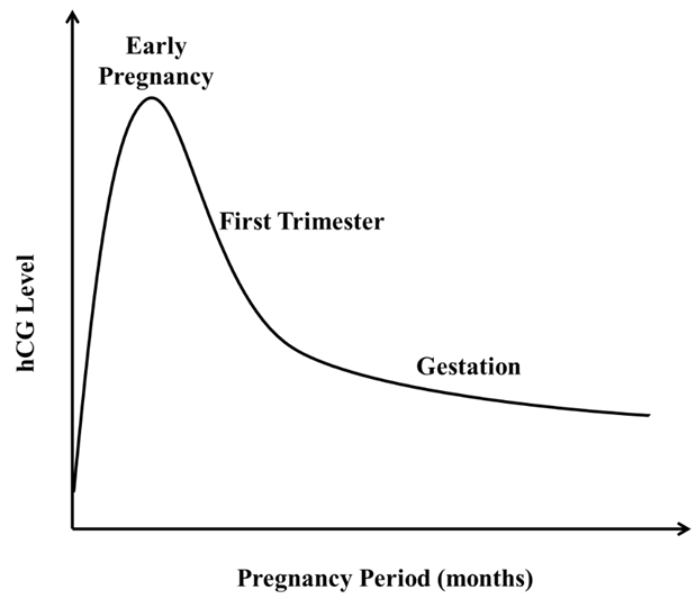

Fig. 5: Graphical representation of Human Chorionic Gonadotropin (hCG) level during pregnancy. The highest peak during early pregnancy indicates the higher hCG level and the descending peak suggest a gradual reduction in hCG level during the gestation period.

The pattern changes of elevated hCG along with other hormones such as progesterone, prolactin, and placental lactogen, besides the loss of cyclical elevations in serum estradiol, initiates the leptin secretion in placenta and leptin resistance (Murphy et al., 2009; Wauman et al., 2017). The leptin production is maintained altogether by the placental production and increased estradiol levels during gestation (Llaneza et al., 2014). Leptin has some pleiotropic effects that play a crucial role in fetal development and adequate placental function including implantation, placental angiogenesis, placental nutrient transport, immune modulation and trophoblast mitogenesis (Tong and $\mathrm{Xu}, 2012$; Farr et al., 2015). The leptin level in cord blood is in relation to the leptin level in fetal growth (Khalaf, 2010). The placental leptin modulates the transport of nutrients, especially amino acids and lipids from mother to fetus (Wasim, 2015). In the white adipose tissue (WAT) of obese pregnancies, the placental damage and dysfunction are stimulated in the placental stromal layer by the release of proinflammatory cytokines, such as IL-6 and TNF $\alpha$ by activated macrophages, as leptin functions as a pro-inflammatory signal (Zhou and Rui, 2013).

\section{LEPTIN IN MENOPAUSAL WOMEN}

Menopause is a natural biological process; it is the cessation of the ovaries function and puts an end to the production of estrogen and progesterone. This ovarian function declines with age, which causes an increase in loss of bone mass, increase in adipose mass and decrease in muscle mass. Visceral leptin also plays a major role in maintaining neuroendocrine regulation and bone metabolism in postmenopausal women (Carter et al., 2013). Aging in women is a crucial feature for developing leptin resistance which triggers metabolic dysregulations and also blunts normal central functions of leptin (Upadhyay et al., 2015). Leptin resistance will lead to decrease in thermogenesis, which contributes to the negative metabolic changes associated with unhealthy aging. The estrogen plays a central role in regulating reproduction and also contributes to regulating energy balance. Estrogen is a vital component in the formation of bones, and also helps protect the cardiovascular system from heart disease. After the menopause, due to a deficiency in estrogen, the bones can become thin and fragile and highly prone to fractures and also which causes osteoporosis and heart attack, which is characterized by predominant abdominal fat accumulation (Sullivan et al., 2017).

Osteoporosis, a multifactorial systemic skeletal disease characterized by low bone mineral density (BMD) and microarchitectural deterioration of bone tissue results in bone fragility and increases the risk of breakage of bones (Kocyigit et al., 2013; Ji and $\mathrm{Xu}, 2015)$. During the menopausal transition period, women will encounter a number of troublesome symptoms, such as hot flashes, night sweats, vaginal atrophy and dryness, dyspareunia, sleep disturbance, and mood swings (Lizcano and Guzman, 2014; Chen and Yang, 2015). Hypertension prevalence in postmenopausal women is higher than it is in premenopausal women and also the prevalence of obesity may be as high as $40 \%$ (Petzel, 2007). If estrogen replacement therapy is instituted soon after the onset of these changes, much of this bone loss, and subsequent fractures can be prevented. Estrogen, activated through the hypothalamic-pituitary-gonadal axis by leptin, itself stimulate the growth of human osteoblasts (Huang et al., 2017). Estrogen deficiency promotes feeding and weight gain, and to some extent, it mimics some actions of leptin. So by the regulation of estrogen and leptin in the menopause women will be a better way for the alleviation of a post-menopausal symptom.

\section{CONCLUSION}

The understanding about the relationship between metabolic systems, reproductive systems, neurohormonal causes of perturbations of puberty and fertility was made clear after the discovery of adipose-hormone; leptin in 1994. A woman drives diverse aspects throughout her life journey from adolescence to mature adult. Many studies have established that leptin deficiency or resistance can be related with anomalous reproductive function. Leptin deficiency and or leptin resistance will inhibit the secretion of FSH (Follicle stimulating hormone) and LH from pituitary which may, in turn, cause infertility. Inadequate nutrition leads intervention of leptin signaling may have a pathophysiological role in reproductive disorders and metabolic alterations. Leptin is a key player in regulating energy homeostasis, neuroendocrine function and metabolism, directing its action on hypothalamic-pituitary 
axis, whose molecular and cellular aspects are progressively being disentangled.

Leptin also plays crucial roles in angiogenesis, immune function, puberty, fertility, and bone formation. In the female, minimal leptin threshold has a permissive role in nutritional and metabolic rate for the onset of puberty and continuity of menstrual cycle. It acts as an important signal that depends on the tolerability of nutritional status for reproductive function. The deviation of leptin from the normal threshold level may affect the neuroendocrine pathways and causes detrimental effects on reproduction. Elevation of leptin in the follicular fluid may negatively affect the embryo development, quality, implantation and pregnancy rates. Leptin acts as a novel placental hormone take part in the control of fetal growth and development. Leptin also has a crucial role in bone metabolism, after menopause bones can become fragile and cause low bone mass density (BMD). So in female leptin plays a pivotal role throughout her entire life to cross several landmarks on time.

\section{ACKNOWLEDGMENTS}

The authors are very thankful to the management of VIT for providing the fund and necessary infrastructure to carry out the work.

\section{CONFLICT OF INTEREST}

The authors declare that no conflicts for this article.

\section{REFERENCES}

Abizaid A, Horvath TL. Ghrelin and the central regulation of feeding and energy balance. Indian journal of endocrinology and metabolism, 2012; 16:617-626.

Anum H, Lubna N, Nazneen Z, Ghazala Y. Comparison of causes and risk factors in middle-aged and young women. World Wide Journal of Multidisciplinary Research and Development, 2015; 1:34-39.

Beymer M, Henningsen J, Bahougne T, Simonneaux V. The role of kisspeptin and RFRP in the circadian control of female reproduction. Molecular and cellular endocrinology, 2016; 438:89-99.

Blüher S, Mantzoros CS. Leptin in humans: lessons from translational research. The American journal of clinical nutrition, 2009; 89(3):991-997.

Blüher S, Mantzoros CS. Leptin in reproduction. Current Opinion in Endocrinology, Diabetes and Obesity, 2007; 14(6):458-464.

Briffa JF, McAinch AJ, Romano T, Wlodek ME, Hryciw DH. Leptin in pregnancy and development: a contributor to adulthood disease? American Journal of Physiology-Endocrinology and Metabolism, 2014; 308(5):335-350.

Brown LM, Clegg DJ. Estrogen and leptin regulation of endocrinological features of anorexia nervosa. Neuropsychopharmacology, 2013; 38(1):237.

Budak E, Sánchez MF, Bellver J, Cerveró A, Simón C, Pellicer A. Interactions of the hormones leptin, ghrelin, adiponectin, resistin, and PYY3-36 with the reproductive system. Fertility and Sterility, 2006; 85(6):1563-1581

Carter S, Caron A, Richard D, Picard F. Role of leptin resistance in the development of obesity in older patients. Clin Interv Aging, 2013; 8:829-844.

Castellano JM, Tena-Sempere M. Metabolic control of female puberty: potential therapeutic targets. Expert opinion on therapeutic targets, 2016; 20(10):1181-93.

Catteau A, Caillon H, Barriere P, Denis MG, Masson D, Freour T. Leptin and its potential interest in assisted reproduction cycles. Human reproduction update, 2016; 22(3):320-341.
Chen XX, Yang T. Roles of leptin in bone metabolism and bone diseases. Journal of bone and mineral metabolism, 2015; 33(5):474-485.

Chou SH, Mantzoros C. 20 years of leptin: role of leptin in human reproductive disorders. Journal of Endocrinology, 2014; 223(1):4962.

Clarke H, Dhillo WS, Jayasena CN. Comprehensive review on kisspeptin and its role in reproductive disorders. Endocrinology and Metabolism, 2015; 30(2):124-141.

Cowley MA, Smart JL, Rubinstein M, Cerdán MG, Diano S, Horvath TL, Cone RD, Low MJ. Leptin activates anorexigenic POMC neurons through a neural network in the arcuate nucleus. Nature, 2001; 411(6836):480-484.

Crain DA, Janssen SJ, Edwards TM, Heindel J, Ho SM, Hunt P, Iguchi T, Juul A, McLachlan JA, Schwartz J, Skakkebaek N. Female reproductive disorders: the roles of endocrine-disrupting compounds and developmental timing. Fertility and Sterility, 2008; 90(4):911-40.

Crujeiras AB, Carreira MC, Cabia B, Andrade S, Amil M, Casanueva FF. Leptin resistance in obesity: an epigenetic landscape. Life sciences, 2015; 140:57-63.

Dardeno TA, Chou SH, Moon HS, Chamberland JP, Fiorenza CG, Mantzoros CS. Leptin in human physiology and therapeutics. Frontiers in neuroendocrinology, 2010; 31(3):377-393.

David L-S, Placido L. Assessment of follicular fluid leptin levels and insulin resistance as outcome predictors in women undergoing in vitro fertilization-intracytoplasmic sperm injection. Fertil Steril, 2014; 102:1619-1625.

De Bond JA, Smith JT. Kisspeptin and energy balance in reproduction. Reproduction, 2014; 147(3):53-63.

Dubern B, Clement K. Leptin and leptin receptor-related monogenic obesity. Biochimie, 2012; 94(10):2111-2115.

Elias CF. Leptin action in pubertal development: recent advances and unanswered questions. Trends in Endocrinology \& Metabolism, 2012; 23(1):9-15.

Farhood MF, Hamdan FB, Al-Salihi AR. Evaluation of Leptin in Sera and Follicular Fluids of Infertile Women Undergoing IntraCytoplasmic Sperm Injection and Their Effects on Pregnancy Outcome. Iraqi Journal of Medical Sciences, 2016; 14(2):146-152.

Farr OM, Tsoukas MA, Mantzoros CS. Leptin and the brain: influences on brain development, cognitive functioning and psychiatric disorders. Metabolism-Clinical and Experimental, 2015; 64(1):114-130.

Gao Q, Horvath TL. Cross-talk between estrogen and leptin signaling in the hypothalamus. American Journal of PhysiologyEndocrinology and Metabolism, 2008; 294(5):817-826.

Gautron L, Elmquist JK. Sixteen years and counting: an update on leptin in energy balance. The Journal of clinical investigation, 2011; 121(6):2087-2093

González RR, Simón C, Caballero-Campo P, Norman R, Chardonnens D, Devoto L, Bischof P. Leptin and reproduction. Human Reproduction Update, 2000; 6(3):290-300.

Goumenou AG, Matalliotakis IM, Koumantakis GE, Panidis DK. The role of leptin in fertility. European Journal of Obstetrics and Gynecology and Reproductive Biology, 2003; 106(2):118-124.

Gueorguiev M, Góth MI, Korbonits M. Leptin and puberty: a review. Pituitary, 2001; 4(1-2):79-86.

Han SK, Gottsch ML, Lee KJ, Popa SM, Smith JT, Jakawich SK, Clifton DK, Steiner RA, Herbison AE. Activation of gonadotropinreleasing hormone neurons by kisspeptin as a neuroendocrine switch for the onset of puberty. Journal of Neuroscience, 2005; 25(49):11349-11356.

Hausman GJ, Barb CR, Lents CA. Leptin and reproductive function. Biochimie, 2012; 94(10):2075-2081.

Henson MC, Castracane VD. Leptin in pregnancy. Biol Reprod, 2000; 63:1219-28.

Herrid M, Palanisamy SK, Ciller UA, Fan R, Moens P, Smart NA, McFarlane JR. An updated view of leptin on implantation and pregnancy: a review. Physiological research, 2014; 63(5):543-557.

Huang WY, Chang CC, Chen DR, Kor CT, Chen TY, Wu HM. 
Circulating leptin and adiponectin are associated with insulin resistance in healthy postmenopausal women with hot flashes. PloS one, 2017; 12(4):0176430.

Jalilian N, Haghnazari L, Rasolinia S. Leptin and body mass index in polycystic ovary syndrome. Indian journal of endocrinology and metabolism, 2016; 20(3):324.

Javed Z, Qamar U, Sathyapalan T. The role of kisspeptin signalling in the hypothalamic-pituitary-gonadal axis - current perspective. Endokrynologia Polska, 2015; 66(6):534-547.

Ji MX, Yu Q. Primary osteoporosis in postmenopausal women. Maturitas, 2015; 82(3):315.

Joo JK, Joo BS, Kim SC, Choi JR, Park SH, Lee KS. Role of leptin in improvement of oocyte quality by regulation of ovarian angiogenesis. Animal reproduction science, 2010; 119:329-334.

Kamyabi Z, Gholamalizade T. A comparative study of serum and follicular fluid leptin concentrations among explained infertile, unexplained infertile and fertile women. International journal of fertility \& sterility, 2015; 9(2):150-156.

Karoutsos P, Karoutsou E and Karoutsos D. Obesity and Female Fertility: The Bridging Role of Leptin. Journal of Data Mining in Genomics \& Proteomics, 2017; 8(1):1-4.

Kelesidis T, Kelesidis I, Chou S, Mantzoros CS. Narrative review: the role of leptin in human physiology: emerging clinical applications. Annals of internal medicine, 2010; 152(2):93-100.

Khalaf BH. Leptin levels in relation to marital status and neuroendocrine function in Iraqi females with polycystic ovary syndrome. Saudi Pharmaceutical Journal, 2010; 18:41-44.

Klok MD, Jakobsdottir S, Drent ML. The role of leptin and ghrelin in the regulation of food intake and body weight in humans: a review. Obesity Reviews, 2007; 8(1):21-34.

Kocyigit H, Bal S, Atay A, Koseoglu M, Gurgan A. Plasma leptin values in postmenopausal women with osteoporosis. Bosn J Basic Med Sci, 2013; 13:193-196.

Könner AC, Brüning JC. Mapping leptin's link to reproduction. Molecular Metabolism, 2012; 1(1):5-7.

Kumari P, Jaiswar SP, Shankhwar P, Deo S, Ahmad K, Iqbal B, Mahdi AA. Leptin as a Predictive Marker in Unexplained Infertility in North Indian Population. Journal of clinical and diagnostic research: JCDR, 2017; 11(3):28-31.

Lecke SB, Morsch DM, Spritzer PM. Leptin and adiponectin in the female life course. Brazilian Journal of Medical and Biological Research, 2011; 44(5):381-387.

Leshan RL, Pfaff DW. The hypothalamic ventral premammillary nucleus: a key site in leptin's regulation of reproduction. Journal of chemical neuroanatomy, 2014; 61:239-247.

Lizcano F, Guzmán G. Estrogen deficiency and the origin of obesity during menopause. BioMed research international, 2014; 2014 Article ID-757461.

Louis GW, Greenwald-Yarnell M, Phillips R, Coolen LM, Lehman MN, Myers Jr MG. Molecular mapping of the neural pathways linking leptin to the neuroendocrine reproductive axis. Endocrinology, 2011; 152(6):2302-2310

Luo Q, Li W, Li M, Zhang X, Zhang H. Leptin/leptinRkisspeptin/kiss1r-GnRH pathway reacting to regulate puberty onset during negative energy balance. Life sciences, 2016; 153:207-212.

Manfredi-Lozano M, Roa J, Ruiz-Pino F, Piet R, Garcia-Galiano D, Pineda R, Zamora A, Leon S, Sanchez-Garrido MA, Romero-Ruiz A, Dieguez C. Defining a novel leptin-melanocortin-kisspeptin pathway involved in the metabolic control of puberty. Molecular Metabolism, 2016; 5(10):844-857.

Murphy VE, Smith R, Giles WB, Clifton VL. Endocrine Regulation of Human Fetal Growth: The Role of the Mother, Placenta, and Fetus. Endocrine Reviews, 2009; 27:141-169.

Mutaz SA. Correlation between follicular fluid leptin and the pregnancy rate in women who underwent. International Journal of Current Research, 2015; 7:24274-24277.
Naylor C, Petri WA, Jr. Leptin regulation of immune responses. Trends in molecular medicine, 2016; 22(2):88-98.

Nishimura TE, Polgreen PM, Polgreen LA, Brandt DS, Thomas KM, Scroggins SM, Evans NJ, Alexander LB, Santillan MK, Santillan DA. Determining the role of Maternal Leptin and Activity in Pregnancy Outcomes. The FASEB Journal, 2017; 31:692-2.

Nogueiras R, Tschöp MH, Zigman JM. Central Nervous System Regulation of Energy Metabolism. Annals of the New York Academy of Sciences, 2008; 1126(1):14-19.

Nunziata A, Borck G, Funcke JB, Kohlsdorf K, Brandt S, Hinney A. Moepps B, Gierschik P, Debatin, KM, Fischer-Posovszky P, Wabitsch M. Estimated prevalence of potentially damaging variants in the leptin gene. Mol Cell Pediatr, 2017; 4(1): 10.

Olaniyan T, Meraiyebu, Auta K, Dare JB, Anjorin YD, Shafe MO. Kisspeptin system: A Multi-Homeostatic System. Journal of Pharmacy and Biological Sciences (IOSR-JPBS), 2013; 5:87-101.

Pan H, Li N, Wu Q. The changes of serum leptin and kisspeptin levels in Chinese children and adolescents in different pubertal stages. International journal of endocrinology, 2016; 2016:11.

Pankov YA. Kisspeptin and leptin in the regulation of fertility. Molecular Biology, 2015; 49(5):631-637.

Paris F, Gaspari L, Sultan C. Maturation of the HypothalamicPituitary-Ovarian Axis and the Onset of Puberty. In Frontiers in Gynecological Endocrinology, 2017; 4:57-65.

Park HK, Ahima RS. Physiology of leptin: energy homeostasis, neuroendocrine function and metabolism. Metabolism-Clinical and Experimental, 2015; 64(1):24-34.

Patterson CM, Villanueva EC, Greenwald M, Rajala M, Gonzalez IE, Saini N, Jones J, Myers MG. Leptin action via LepR-b Tyr 1077 contributes to the control of energy balance and female reproduction. Molecular Metabolism, 2012; 1:61-69.

Pérez-Pérez A, Sánchez-Jiménez F, Maymó J, Dueñas JL, Varone C, Sánchez-Margalet V. Role of leptin in female reproduction. Clinical Chemistry and Laboratory Medicine (CCLM), 2015; 53(1):15-28.

Perry B, Wang Y. Appetite regulation and weight control: the role of gut hormones. Nutrition \& diabetes, 2012; 2(1):26.

Petzel M. Action of leptin on bone and its relationship to menopause. Biomed Pap Med FacUnivPalacky Olomouc Czech Repub, 2007; 151:195-199.

Ratra DV, Elias CF. Chemical identity of hypothalamic neurons engaged by leptin in reproductive control. Journal of chemical neuroanatomy, 2014; 61:233-238.

Rhie YJ, Lee KH, Ko JM, Lee WJ, Kim JH, Kim HS. KISS1 gene polymorphisms in Korean girls with central precocious puberty Journal of Korean medical science, 2014; 29(8):1120-1125.

Roa J, Aguilar E, Dieguez C, Pinilla L, Tena-Sempere M. New frontiers in kisspeptin/GPR54 physiology as fundamental gatekeepers of reproductive function. Frontiers in neuroendocrinology, 2008; 29(1):48-69.

Roseweir AK, Millar RP. The role of kisspeptin in the control of gonadotrophin secretion. Human reproduction update, 2008; 15(2):203212.

Salem H, Rosenfeld T, Altarescu G, Grisaru-Granovsky S, Birk R. Maternal and neonatal leptin and leptin receptor polymorphisms associated with preterm birth. Gene, 2016; 591(1):209-13

Sam AH, Dhillo WS. Endocrine links between fat and reproduction. The Obstetrician \& Gynaecologist, 2010; 12(4):231-236.

Sanchez-Garrido MA, Tena-Sempere M. Metabolic control of puberty: roles of leptin and kisspeptins. Hormones and Behaviour, 2013; 64(2):187-194

Semaan SJ, Tolson KP, Kauffman AS. The development of kisspeptin circuits in the Mammalian brain. In Kisspeptin Signaling in Reproductive Biology, 2013; 784:221-252.

Sheffer-Babila S, Sun Y, Israel DD, Liu SM, Neal-Perry G, Chua SC, Jr. Agouti-related peptide plays a critical role in leptin's effects on female puberty and reproduction. American Journal of PhysiologyEndocrinology and Metabolism, 2013; 305(12):1512-1520. 
Skorupskaite K, George JT, Anderson RA. The kisspeptin-GnRH pathway in human reproductive health and disease. Human reproduction update, 2014; 20(4):485-500.

Sroga-Rios JM, Martinez AM, Cool DR, DiPaola KB, Lindheim SR. Elevated levels of diabetes-associated peptide hormones in the follicular fluid and serum of obese polycystic ovary syndrome patients are associated with suboptimal ovarian response. IVF Lite, 2016; 3(3):110.

Stieg MR, Sievers C, Farr O, Stalla GK, Mantzoros CS. Leptin: a hormone linking activation of neuroendocrine axes with neuropathology. Psychoneuroendocrinology, 2015; 51:47-57.

Sullivan SD, Lehman A, Nathan NK, Thomson CA, Howard BV. Age of menopause and fracture risk in postmenopausal women randomized to calcium+ vitamin D, hormone therapy, or the combination: results from the Women's Health Initiative Clinical Trials. Menopause, 2017; 24(4):3718 .

Tafvizi F, Masomi M. Comparison of Serum Leptin Level in Women with Unexplained Infertility and Fertile Women in Iran. The Journal of Obstetrics and Gynecology of India, 2016; 66(1):466-470.

Terasawa E, Guerriero KA, Plant TM. Kisspeptin and puberty in mammals. In Kisspeptin Signaling in Reproductive Biology, 2013; 784:253-273.

Tng EL. Kisspeptin signalling and its roles in humans. Singapore medical journal, 2015; 56(12):649-656

Tong Q, Xu Y. Central leptin regulation of obesity and fertility. Current obesity reports, 2012; 1:236-244.

Tsouma I, Kouskouni E, Gennimata V, Demeridou S, Boutsikou M, Grigoriou V, Chasiakou A, Hassiakou S, Baka S. Leptin levels in women with polycystic ovaries undergoing ovarian stimulation: relation to lipoprotein profiles. In Vivo, 2014; 28(5):989-992.

Unuane D, Tournaye H, Velkeniers B, Poppe K. Endocrine disorders \& female infertility. Best Practice \& Research Clinical Endocrinology \& Metabolism, 2011; 25(6):861-873.

Upadhyay J, Farr OM, Mantzoros CS. The role of leptin in regulating bone metabolism. Metabolism-Clinical and Experimental, 2015; 64(1):105-113.

Vázquez MJ, Romero-Ruiz A, Tena-Sempere M. Roles of leptin in reproduction, pregnancy and polycystic ovary syndrome: consensus knowledge and recent developments. Metabolism-Clinical and Experimental, 2015; 64(1):79-91.

Vehapoğlu A, Türkmen S, Terzioğlu Ş. Alpha-melanocytestimulating hormone and agouti-related protein: do they play a role in appetite regulation in childhood obesity? Journal of clinical research in pediatric endocrinology, 2016; 8(1):40-47.

Wasim M. Role of Leptin in Obesity. J Obes Weight Loss Ther, $2015 ; 5: 258$.

Wauman J, Zabeau L, Tavernier J. The Leptin Receptor Complex: Heavier Than Expected? Frontiers in endocrinology, 2017; 8:30. Zhou Y, Rui L. Leptin signaling and leptin resistance. Frontiers of medicine, 2013; 7(2):207-222.

How to cite this article:

Saranya GM, Pathy MR. Insights into the putative role of leptin in various traversing stages of women: A narrative review. J App Pharm Sci, 2018; 8(07): 141-148. 